\title{
Lugano Classification Stage IE Hodgkin Lymphoma AJCC v8
}

National Cancer Institute

\section{Source}

National Cancer Institute. Lugano Classification Stage IE Hodgkin Lymphoma A/CC v8. NCI Thesaurus. Code C141171.

Stage IE: Single extralymphatic site in the absence of nodal involvement (rare in Hodgkin lymphoma). (from AJCC 8th Ed.) 